\title{
Common rs5918 (PIA1/A2) polymorphism in the ITGB3 gene and risk of coronary artery disease
}

\author{
Mehri Khatami ${ }^{1}$, Mohammad Mehdi Heidari ${ }^{1}$, Sorour Soheilyfar ${ }^{2}$
}

${ }^{1}$ Department of Biology, Faculty of Science, Yazd University, Yazd, Iran ${ }^{2}$ Department of Biology, Ashkezar Islamic Azad University, Ashkezar, Yazd, Iran

Submitted: 26 March 2016

Accepted: 7 April 2016

Arch Med Sci Atheroscler Dis 2016; 1: e9-e15

DOI: 10.5114/amsad.2016.59587

Copyright $\odot 2016$ Termedia \& Banach

\section{Abstract}

Introduction: The $T$ to $C$ transition at nucleotide 1565 of the human glycoprotein IIIa (ITGB3) gene represents a genetic polymorphism (PIA1/A2) that can influence both platelet activation and aggregation and that has been associated with many types of disease. Here, we present a newly designed multiplex tetra-primer amplification refractory mutation system - polymerase chain reaction (T-ARMS-PCR) for genotyping a single nucleotide polymorphism (SNP) (dbSNP ID: rs5918) in the human ITGB3 gene.

Material and methods: We set up T-ARMS-PCR for the rs5918 SNP in a single-step PCR and the results were validated by the PCR-RFLP method in 132 coronary artery disease (CAD) patients and 122 unrelated healthy individuals. Results: Full accordance was found for genotype determination by the PCR-RFLP method. The multiple logistic regression analysis showed a significant association of the rs5918 polymorphism and CAD according to dominant and recessive models (dominant model OR: $2.40,95 \% \mathrm{Cl}: 1.33-4.35$; $p=0.003$, recessive model OR: $4.71,95 \% \mathrm{Cl}: 1.32-16.80 ; p=0.0067$ ).

Conclusions: Our T-ARMS-PCR in comparison with RFLP and allele-specific PCR is more advantageous because this PCR method allows the evaluation of both the wild type and the mutant allele in the same tube. Our results suggest that the rs5918 (PIA1/A2) polymorphism in the ITGB3 gene may contribute to the susceptibility of sporadic Iranian coronary artery disease (CAD) patients.

Key words: glycoprotein IIIa PIA1/A2 polymorphism, rs5918, T-ARMS-PCR, coronary artery disease.

\section{Introduction}

Coronary artery disease (CAD) is most commonly due to atherosclerotic occlusion of the coronary arteries and is the leading cause of death worldwide for both men and women [1]. Coronary artery disease occurs when plaque builds up inside the coronary arteries and can involve many blood vessels with a variety of presentations [2]. This can lead to coronary artery disease or heart failure and arrhythmias. The conventional risk factors for CAD such as elevated cholesterol, hypertension, obesity, and smoking were well associated with $30-40 \%$ increasing in mortality and morbidity [3]. Multiple epidemiological, family, and other factors have documented a genetic predisposition for CAD [4]. Most polygenic diseases such as CAD are due to several common genes and have their genetic predisposition transmitted by multiple genes [5]. In polygenic disorders many DNA markers and single nucleotide polymorphisms (SNPs) of unrelated individuals need to be analyzed by different methods. A greater

\author{
Corresponding author: \\ Mehri Khatami \\ Department of Biology \\ Faculty of Science \\ Yazd University \\ 89195-741 Yazd, Iran \\ Phone: +983531233013 \\ Fax: +98 3538210644 \\ E-mail: M.khatami@yazd.ac.ir
}


frequency of a SNP in patients indicates the SNP is in close proximity to a genetic risk variant for the disease. These variants strongly show the importance of a genetic predisposition for CAD and also confirm that these SNPs are even more common than expected [6]. However, it is well recognized that certain genes will relate to plaque rupture and/or thrombosis, and the beginning of the process of atherosclerosis. Glycoprotein IIIa (GPIIla) or the beta subunit of the platelet membrane adhesive protein receptor complex GP IIb/IIla is coded by the ITGB3 gene, and is a surface protein found in various tissues, participating in cell-surface mediated signaling and cell adhesion [7]. The exons and introns of the entire ITGB3 gene have been demonstrated to contain many polymorphic regions, one of which was found to be associated with cardiovascular diseases. This common ITGB3 polymorphism at codon 33 of exon 2 (T1565C, dbSNP ID: rs5918) corresponds to the polymorphism of amino acid residues (leucine/proline) at position 33 (PIA1/A2) of the polypeptide chain. It has been reported that this SNP is a risk factor of many types of disease, such as myocardial infarction [8], coronary heart disease, type 2 diabetes, asthma $[9,10]$, many cancers including colon, non-Hodgkin lymphoma [11], breast [12-14] ovarian cancer [15] and kidney cancer [16]. It has also been documented that the platelets bearing the $\beta 3$ subunit of integrin $\alpha$ llb $\beta 3$ with a proline at position 33 are characterized by an increased risk for aggregation and immunogenic properties of platelets [3,4]. Since the amount of platelet aggregates is increased in carriers of the PIA2 allele with $C A D$, it is of interest to determine whether this polymorphic variant is associated with this disease. The previous data on the association of the polymorphic marker PIA1/A2 of the ITGB3 gene with both arterial and venous thrombosis in various ethnic groups $[5,6]$ are contradictory $[17$, 18]. The presence of the PIA2 allele is associated with an increased binding affinity to fibrinogen as well as with platelet aggregability in response to epinephrine, adenosine diphosphate and collagen in vitro [19]. Several studies have suggested that the PIA2 allelic variant causes an altered sensitivity to aspirin and an increased sensitivity to platelet aggregation by various agonists [20, 21].

Single nucleotide polymorphism (SNP) genotyping has been done by PCR-RFLP, real time-PCR and direct sequencing methods [22-24]. These techniques have certain limitations and are relatively slow and very expensive, and fewer reactions are catalyzed per kit in comparison to the tetra primer-amplification refractory mutation system-PCR (T-ARMS-PCR). With this method, the genotyping could be done using only a thermocycler machine at the least time, and can be used to genotyping of essential SNPs in the entire genome.
In conventional ARMS PCR, the amplification of the normal and mutant allele is done in two separate reactions, but in T-ARMS-PCR, we can amplify both the normal and mutant allele with a control fragment in a single reaction. In the T-ARMS-PCR method two outer, non-allele-specific primers and two inner, allele-specific primers in opposite orientation to each other are used.

The outer primers amplify a large fragment of the target gene containing a variant nucleotide as a control fragment and smaller allele-specific amplicons with different sizes that can easily be discriminated in gel electrophoresis either as homozygous or heterozygous. A deliberate mismatch at position $2^{\text {nd }}$ or $3^{\text {rd }}$ nucleotide from the $3^{\prime}$ terminal end of the inner primers can improve allele specificity [25].

The results of a meta-analysis of research showed that the PIA2 variant was associated with an increased risk of coronary heart disease [26, 27]. Some reports suggest that PIA1/A2 heterozygotes are prone to thrombotic disease, whereas $\mathrm{PIA} 1 / \mathrm{A} 1$ homozygotes may be prone to early atherosclerosis and more rapid progression of stable coronary artery disease [10]. Presently, we are developing a rapid single-step method using T-ARMSPCR for detection of Leu33Pro (PIA1/A2), which is a possible SNP in cardiovascular diseases studies.

\section{Material and methods}

\section{Patients and DNA extraction}

This study was performed on 132 patients selected from 412 patients who referred to cardiac centers in Afshar Hospital (Yazd, Iran) due to symptoms of myocardial infarction between 2012 and 2015. Patients had major lesions (> 50\% narrowing of luminal diameter) in one, two, or three vessels ( $L A D, L C X$, and RCA) that were candidate vessels for coronary artery bypass graft surgery. CAD patients were identified according to the coronary angiography guidelines [28].

When up to $50 \%$ blockage was observed in the major epicardial coronaries and their branches associated with stenotic lesions, coronary arterial disease was considered to be present. We also chose 122 unrelated healthy individuals matched for age, sex, and ethnicity with normal or near-normal angiography reports (no lesion greater than $30 \%$ ) as a control group (Table I). All of the patients and the control group were informed of the aims of the study and gave their informed consent for the genetic analysis. Genomic DNA was isolated from the peripheral blood samples using a DNA isolation kit (DNAfast Kit-Genfanavaran, Tehran, Iran).

\section{Primer design and bioinformatics analysis}

A common missense rs5918 (PIA1/A2) polymorphism in the ITGB3 gene was selected (http:// 
Table I. Clinical characteristics of coronary atherosclerosis patients

\begin{tabular}{|lccc|}
\hline Parameter & Patients $(n=132)$ & Controls $(n=122)$ & $P$-value \\
\hline Male gender (\%) & 75 & 71 & 0.670 \\
\hline Age [years] & $52.6 \pm 6.8$ & $52.6 \pm 6.9$ & 0.56 \\
\hline Smokers (\%) & 28 & 23 & 0.517 \\
\hline Body mass index $\left[\mathrm{kg} / \mathrm{m}^{2}\right]$ & $26.1 \pm 2.4$ & $25.3 \pm 1.9$ & 0.0012 \\
\hline Cholesterol $[\mathrm{mg} / \mathrm{dll}]$ & $214.9 \pm 52.8$ & $181.1 \pm 36.8$ & 0.001 \\
\hline LDL-C $[\mathrm{mg} / \mathrm{dl}]$ & $128.7 \pm 43.4$ & $118.2 \pm 44.1$ & 0.145 \\
\hline HDL-C [mg/dl] & $45.4 \pm 8.5$ & $46.9 \pm 11.2$ & 0.456 \\
\hline TGs $[\mathrm{mg} / \mathrm{dl}]$ & $205.7 \pm 102.1$ & $153.4 \pm 96.1$ & 0.014 \\
\hline
\end{tabular}

Table II. PCR primers and conditions

\begin{tabular}{|c|c|c|c|}
\hline \multirow{5}{*}{$\begin{array}{l}\text { ITGB3 } \\
\text { (SNP ID: rs5918) }\end{array}$} & Primer sequence & Temperature $\left[{ }^{\circ} \mathrm{C}\right]$ & Amplicon size \\
\hline & Fo: 5'-GGATTATCCCAGGAAAGACCAC & 66 & \multirow{4}{*}{$\begin{array}{c}\text { T allele (284 bp) } \\
\text { C allele (179 bp) } \\
\text { Control band (424 bp) }\end{array}$} \\
\hline & Ro: 5'-GACTTCCTCCTCAGACCTCCAC-3' & 70 & \\
\hline & Fi: 5'-TGTCTTACAGGCCCTGCCGCT-3' & 68 & \\
\hline & Ri: 5'-GGTCACAGCGAGGTGAGCACG-3' & 70 & \\
\hline
\end{tabular}

www.ncbi.nlm.nih.gov/books/SNP). The four primers used in this research were designed by the online website Primer1: http://primer1.soton.ac.uk/ primer1.html. The specificity of the primers was checked by the 'BLAST' program at http://www. ncbi.nlm.nih.gov/blast (Table II). To enhance the specificity of inner primers, at the $3^{\text {rd }}$ nucleotide from the 3'-terminus changes to destabilizing mismatch.

SWISS-MODEL (http://swissmodel.expasy.org) was used for protein modeling of mutant protein. SWISS-MODEL is a fully automated protein structure homology-modeling server. The PyMol software was used for visualizing the effect of the altered residue on the protein structure.

\section{T-ARMS-PCR and PCR-RFLP analysis}

Polymerase chain reaction was performed in a total volume of $12.5 \mu \mathrm{l}$ containing $50 \mathrm{ng}$ of template DNA, $250 \mathrm{nM}$ of each primer, $250 \mu \mathrm{M}$ dNTPs, $1.5 \mathrm{mM} \mathrm{MgCl}_{2}, 1 \mathrm{X}$ buffer and $0.5 \mathrm{U}$ of Taq polymerase (Yekta Tajhiz Azma, Tehran, Iran). PCR amplification (touchdown) was carried out at $95^{\circ} \mathrm{C}$ for $2 \mathrm{~min}$, followed by denaturation at $95^{\circ} \mathrm{C}$ for $20 \mathrm{~s}$, first annealing at $68^{\circ} \mathrm{C}$ (10 cycles), further $\left(25\right.$ cycles) annealing at $69^{\circ} \mathrm{C}$ for $1 \mathrm{~min}$ and extension at $72^{\circ} \mathrm{C}$ for $50 \mathrm{~s}$, followed by a final extension for $5 \mathrm{~min}$. Non-denaturation polyacrylamide gel electrophoresis (6\%) and silver staining were used for detection of PCR products.

This procedure rendered 2 bands in homozygotes (PIA1/A1 resulting in 424 and 285 bp, and
PIA1/A1 resulting in 424 and $180 \mathrm{bp}$ ) and 3 bands in heterozygotes (424, 285 and 180 bp). Figure 1 shows the products of tetra-primer ARMS-PCR for 5 different genomic DNA samples.

In this study, the concentration of PCR components such as primers, magnesium chloride, dNTP and Taq DNA polymerase were optimized. Beside PCR components, the PCR conditions were also optimized.

The forward (Fo) and reverse (Ro) primers were used to amplify the 424-bp fragment. The 424-bp product was digested with $5 \mathrm{U} \mathrm{Mspl}$ restriction enzyme for $16 \mathrm{~h}$. Fragments were separated by electrophoresis using $6 \%$ polyacrylamide gel electrophoresis. The resulting fragments were 332, 86 and $6 \mathrm{bp}$ for the PIA1 allele and 173, 159, 86 and $6 \mathrm{bp}$ for the PIA2 allele (Figure 1).

\section{Statistical analysis}

The SPSS software (IBM SPSS 22, SPSS Inc., Chicago, IL., USA) was used for statistical analysis. The association between two groups was examined by the $\chi^{2}$ goodness-of-fit test. Multiple logistic regression models (co-dominant, dominant and recessive) were employed to analysis the genetic data. Values of $p<0.05$ were regarded as statistically significant.

\section{Results}

Total DNA samples analyzed with T-ARMS-PCR were re-evaluated by PCR-RFLP analysis using the restriction enzyme Mspl. We obtained $100 \%$ accor- 
A
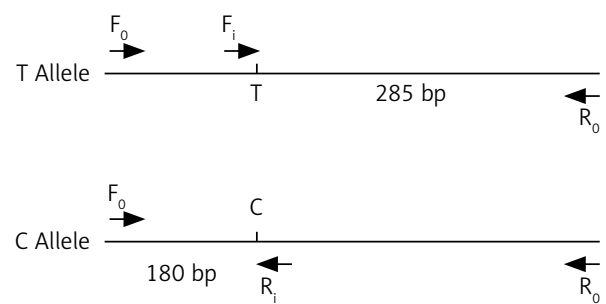

\begin{tabular}{|c|c|}
\hline Genotypes & Fragments [bp] \\
\hline TT & $424-285$ \\
\hline TC & $424-285-180$ \\
\hline CC & $424-180$ \\
\hline
\end{tabular}

B

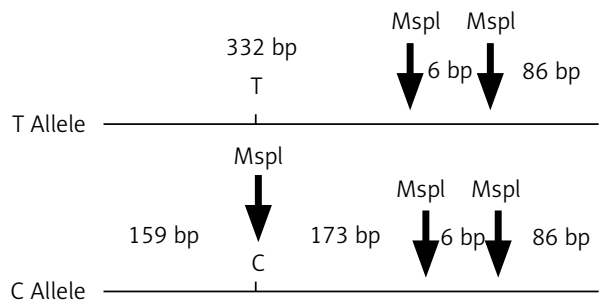

\begin{tabular}{|c|c|}
\hline Genotypes & Fragments [bp] \\
\hline TT & $333-85-6$ \\
\hline TC & $333-173-157-85-6$ \\
\hline CC & $173-157-85-6$ \\
\hline
\end{tabular}
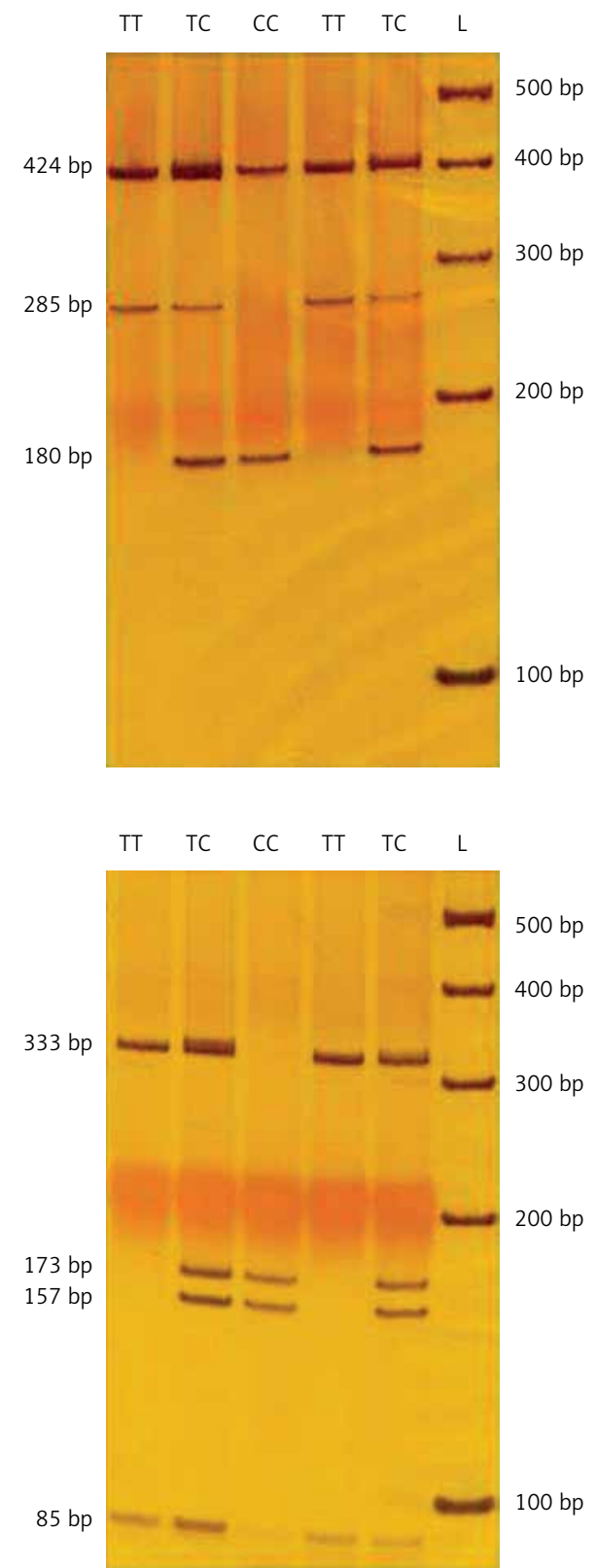

Figure 1. A - Results of T-ARMS-PCR of ITGB3 polymorphism (rs5918); B - validation using PCR-RFLP by Mspl restriction endonuclease

dance between both methods for genotype determination. Mean age (mean \pm SD) was $53.9 \pm 6.8$ and $52.6 \pm 6.9$ years for patients and controls, respectively. Coronary angiography revealed 132 patients (CAD ${ }^{+}$group) with one vessel (LAD) $(n=31)$, two vessels $(\mathrm{LCX})(n=51)$, or three vessels (RCA) $(n=49)$ that were candidate vessels for coronary artery bypass grafting (CABG) and 122 patients (CAD- group) with no angiographically identified narrowing.

Genotype distributions and allelic frequencies of the ITGB3 polymorphism among CAD patients and controls are shown in Table III. The frequency of the ITGB3 C allele was significantly higher in the CAD patients than in the control group $(p<0.001)$.
The multiple logistic regression analysis showed a significant association of the rs5918 polymorphism and CAD according to dominant and recessive models (dominant model OR: $2.40,95 \% \mathrm{Cl}$ : 1.33-4.35; $p=0.003$, recessive model OR: 4.71 , 95\% Cl: $1.32-16.80 ; p=0.0067$ ) (Table III).

\section{Discussion}

So far, several variants of the ITGB3 gene have been described [27]. The correlation of the rs5918 polymorphism with the incidence of CAD was first reported by Marian et al. [29]. In the present study, the allele and genotype frequencies of the polymorphic marker PIA1/A2 of the ITGB3 gene were determined in a group of patients with $C A D$ and 
Table III. Genotype and allele variant frequencies in patients and controls

\begin{tabular}{|lcccc|}
\hline ITGB3(rs5918) & Patients $(n=132)$ & Controls $(n=122)$ & OR $(95 \% \mathrm{Cl})$ & $P$-value \\
\hline $\begin{array}{l}\text { Codominant model: } \\
\text { TT }\end{array}$ & $88(66.67 \%)$ & $101(85.2 \%)$ & 1 & \\
\hline TC & $30(22.7 \%)$ & $18(14.8 \%)$ & $0.523(0.273-1.002)$ & 0.051 \\
\hline CC & $14(10.6 \%)$ & $3(0.0 \%)$ & $0.187(0.052-0.671)$ & 0.010 \\
\hline \begin{tabular}{l} 
Dominant model: \\
\hline TT
\end{tabular} & $88(66.7 \%)$ & $101(82.8 \%)$ & & \\
\hline TC + CC & $44(33.3 \%)$ & $21(17.2 \%)$ & $2.40(1.33-4.35)$ & 0.003 \\
\hline Recessive model: & $14(10.6 \%)$ & $3(2.5 \%)$ & & \\
\hline CC & $118(89.4 \%)$ & $119(97.5 \%)$ & $4.71(1.32-1.608)$ & 0.0067 \\
\hline TC + TT & & & & \\
\hline Allele frequency: & $206(78.0 \%)$ & $220(90.2 \%)$ & & \\
\hline T & $58(22.00 \%)$ & $24(9.8 \%)$ & $0.387(0.232-0.644)$ & $<.001$ \\
\hline C & & & & \\
\hline
\end{tabular}

$O R$ - odds ratio, $\mathrm{Cl}$ - confidence interval.

control subjects. Weiss et al. demonstrated the association of the PIA2 allele with the risk of cardiovascular diseases [30]. PIA2 allele frequency was significantly higher in CAD patients than in control subjects. The frequency distributions of different genotypes and alleles using techniques for detection of the ITGB3 gene in other population studies are described in Table IV [22, 24, 31-33].

Protein modeling based on human ITGB3 protein structure (pdb id: $4 \mathrm{~g} 1 \mathrm{~m}$ ) shows that $\mathrm{L3} 3$ is located on the beta strand of the extracellular domain. ITGB3 is a heterodimer composed of noncovalently associated $a$ and $b$ subunits. These sub- units have a large extracellular domain, a single transmembrane region, and a short cytoplasmic domain $[12,33]$. The L33P change lies in the N-terminal of ITGB3. An analysis of the ITGB3 wild-type and L33P mutant-derived protein structure using the SWISS-MODEL server indicates that three-dimensional structure of the protein is disrupted in the mutant (Figure 2).

In general, the allele and genotype frequency distributions in the Iranian population were similar to those in other populations. Thus, the results of our study suggest that the polymorphic variant PIA1/A2 is associated with CAD in the Iranian population.
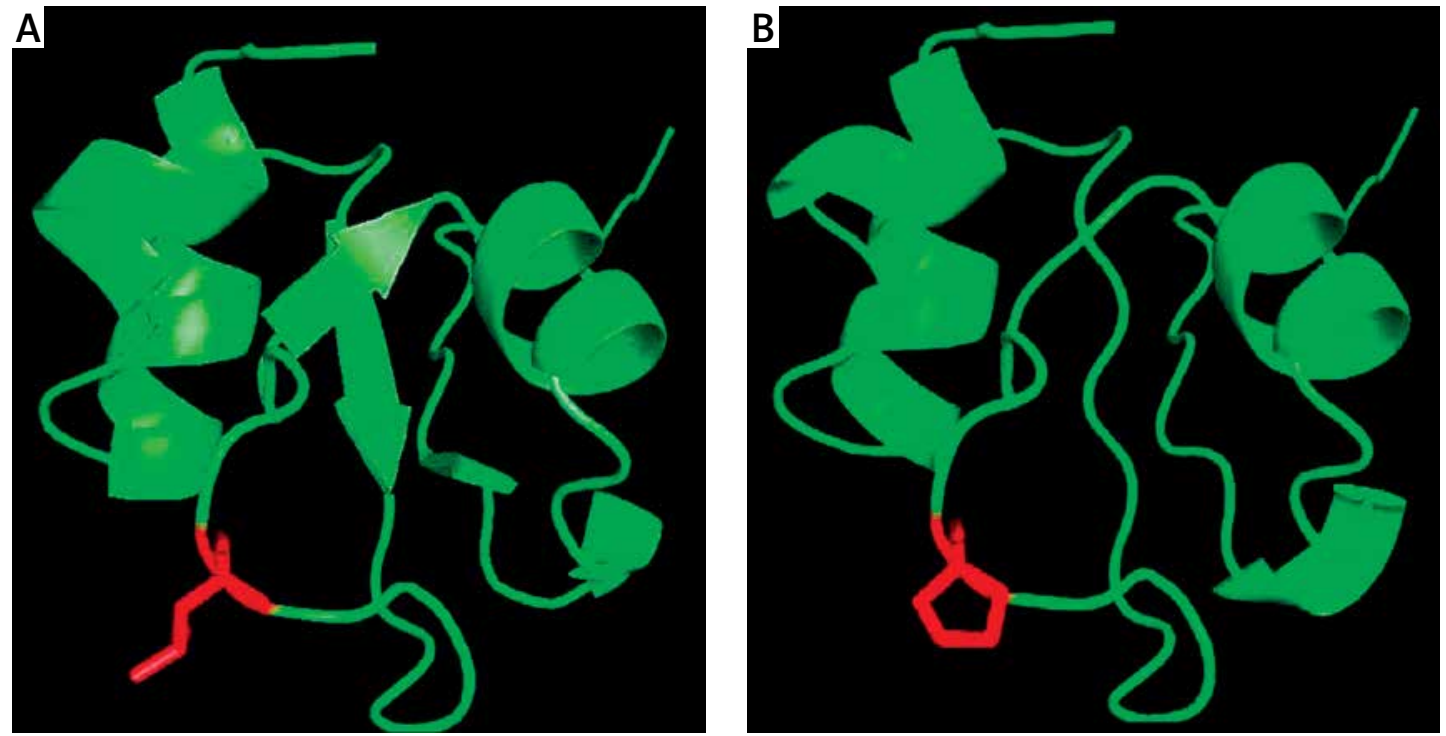

Figure 2. Molecular model of human ITGB3 protein base in PDB file 4g1m showing close-up of the L33 (A) and P 33 residues (B) using PyMol 
Table IV. Distribution of ITGB3 polymorphism in current study in comparison with previously published data

\begin{tabular}{|c|c|c|c|c|c|c|c|c|}
\hline Study & Population & $N$ & & otype & & Alle & (\%) & Genotyping platform \\
\hline (rs5918 SNP) & & & TT & $\mathrm{TC}$ & CC & $T$ & C & \\
\hline Our study & Iranian & 254 & 74.4 & 18.9 & 6.7 & 83.9 & 16.1 & T-ARMS-PCR \\
\hline Torabi et al. & Iranian & 200 & 70 & 14 & 16 & 77 & 23 & PCR-RFLP \\
\hline $\begin{array}{l}\text { Nikolajevic- } \\
\text { Starcevic et al. }\end{array}$ & Slovenia & 342 & 47 & 36.8 & 16.2 & 65.5 & 34.5 & PCR-RFLP \\
\hline Zhang et al. & Chinese & 622 & 96 & 4 & 0 & 98 & 2 & $\begin{array}{l}\text { High-resolution melting } \\
\text { analysis (HRM) }\end{array}$ \\
\hline Yilmaz et al. & Turkish & 184 & 83.7 & 13 & 3.3 & 90.2 & 9.8 & PCR-RFLP \\
\hline Bianconi et al. & Austrian & 109 & 79.8 & 17.4 & 2.8 & 88.5 & 11.5 & PCR-RFLP \\
\hline
\end{tabular}

The common ITGB3 studies have utilized MspI digestion to identify the rs5918 polymorphism. Because this polymorphism is a risk factor in many diseases including cardiovascular diseases and cancers, here we developed a rapid, sensitive and one-step tetra-primer PCR-ARMS method for detection of the rs5918 polymorphism.

The most critical step for successful development of the new multiplex tetra-primer amplification refractory mutation system-PCR method is the primer design. In this study, the primers for amplification of ITGB3 rs5918 were designed using the online website Primer1: http://primer1.soton.ac.uk/primer1.html. Both the outer primers were designed with 21 base pairs (bp) in length and the inner primers were designed with 22 bp with a guanine and adenine located at the $3^{\text {rd }}$ nucleotide from the 3 '-terminus for forward (wild type allele) and reverse (mutant allele) primers to increase their specificity for the template DNA.

Our T-ARMS-PCR in comparison with RFLP and allele-specific PCR is more advantageous because this PCR method allows the evaluation of both the wild type and mutant allele in the same tube. This assay is a reproducible and stable single-tube reaction.

In conclusion, our T-ARMS-PCR needs only a small amount of traditional PCR reagents, without special equipment. Our results suggest that the rs5918 (PIA1/A2) polymorphism in the ITGB3 gene may contribute to the susceptibility to sporadic CAD. Therefore, this procedure could be used in most clinical diagnostic laboratories.

\section{Acknowledgments}

This research was funded by Yazd University. We thank all the patients for providing blood samples for the scientific research, also the Especial Afshar Hospital (Yazd, Iran). The study was approved by Yazd University Human Research Ethics Committee.

\section{Conflict of interest}

The authors declare no conflict of interest.

\section{References}

1. Bolognese L. Changing patterns of ST elevation myocardial infarction epidemiology. Am Heart J 2010; 160: S1-3.

2. Deakin SP, James RW. Genetic and environmental factors modulating serum concentrations and activities of the antioxidant enzyme paraoxonase-1. Clin Sci 2004; 107: 435-47.

3. Franchini M, Peyvandi F, Mannucci PM. The genetic basis of coronary artery disease: from candidate genes to whole genome analysis. Trends Cardiovasc Med 2008; 18: 157-62.

4. Ozaki K, Tanaka T. Molecular genetics of coronary artery disease. J Hum Genet 2016; 61: 71-7.

5. Preuss M, Konig IR, Thompson JR, et al. Design of the Coronary ARtery DIsease Genome-Wide Replication And Meta-Analysis (CARDloGRAM) Study: a genome-wide association meta-analysis involving more than 22000 cases and 60000 controls. Circ Cardiovasc Genet 2010; 3: 475-483.

6. Musunuru K, Kathiresan S. HapMap and mapping genes for cardiovascular disease. Circ Cardiovasc Genet 2008; 1: 66-71.

7. Bennett JS. Structure and function of the platelet integrin alphallbbeta3. J Clin Investig 2005; 115: 3363-9.

8. Floyd CN, Mustafa A, Ferro A. The PIA1/A2 polymorphism of glycoprotein IIla as a risk factor for myocardial infarction: a meta-analysis. PloS One 2014; 9: e101518.

9. Zimrin AB, Gidwitz S, Lord $S$, et al. The genomic organization of platelet glycoprotein Illa. J Biol Chem 1990; 265: 8590-5.

10. Mikkelsson J, Perola M, Laippala P, Penttila A, Karhunen PJ. Glycoprotein IIla PI(A1/A2) polymorphism and sudden cardiac death. J Am Coll Cardiol 2000; 36: 1317-23.

11. Cerhan JR, Ansell SM, Fredericksen ZS, et al. Genetic variation in 1253 immune and inflammation genes and risk of non-Hodgkin lymphoma. Blood 2007; 110: 4455-63.

12. Bojesen SE, Kjaer SK, Hogdall EV, et al. Increased risk of ovarian cancer in integrin beta3 Leu33Pro homozygotes. Endocr Relat Cancer 2005; 12: 945-52.

13. Langsenlehner U, Renner W, Yazdani-Biuki B, et al. Integrin alpha- 2 and beta-3 gene polymorphisms and breast cancer risk. Breast Cancer Res Treat 2006; 97: 67-72. 
14. Jin Q, Hemminki K, Grzybowska E, Klaes R, Soderberg M, Forsti A. Re: Integrin beta3 Leu33Pro homozygosity and risk of cancer. J Natl Cancer Instit 2004; 96: 234-5.

15. Wang-Gohrke S, Chang-Claude J. Integrin beta3 Leu33Pro homozygosity and risk of cancer. J Natl Cancer Instit 2005; 97: 778-9.

16. Kallio JP, Mikkelsson J, Tammela TL, Karhunen PJ, Kellokumpu-Lehtinen P. Genetic variation in platelet integrin alphabeta (GPIlb/IIla) and the metastatic potential of renal cell carcinoma. BJU Intern 2006; 98: 201-4.

17. Feng D, Lindpaintner K, Larson MG, et al. Increased platelet aggregability associated with platelet GPIIla PIA2 polymorphism: the Framingham Offspring Study. Arterioscler Thromb Vasc Biol 1999; 19: 1142-7.

18. Vijayan KV, Liu Y, Dong JF, Bray PF. Enhanced activation of mitogen-activated protein kinase and myosin light chain kinase by the Pro33 polymorphism of integrin beta 3. J Biol Chem 2003; 278: 3860-7.

19. Goodall AH, Curzen N, Panesar M, et al. Increased binding of fibrinogen to glycoprotein IIla-proline33 (HPA-1b, PIA2, Zwb) positive platelets in patients with cardiovascular disease. Eur Heart J 1999; 20: 742-7.

20. Papp E, Havasi V, Bene J, et al. Glycoprotein IIIA gene (PIA) polymorphism and aspirin resistance: is there any correlation? Ann Pharmacother 2005; 39: 1013-8.

21. Cooke GE, Liu-Stratton Y, Ferketich AK, et al. Effect of platelet antigen polymorphism on platelet inhibition by aspirin, clopidogrel, or their combination. J Am Coll Cardiol 2006; 47: 541-6.

22. Nikolajevic-Starcevic J, Petrovic MG, Petrovic D. A1/A2 polymorphism of the glycoprotein Illa gene and diabetic retinopathy in Caucasians with type 2 diabetes. Clin Exp Ophthalmol 2011; 39: 665-72.

23. Jakubowska A, Rozkrut D, Antoniou A, Hamann U, Lubinski J. The Leu33Pro polymorphism in the ITGB3 gene does not modify BRCA1/2-associated breast or ovarian cancer risks: results from a multicenter study among 15,542 BRCA1 and BRCA2 mutation carriers. Breast Cancer Res Treat 2010; 121: 639-49.

24. Zhang Y, Han Y, Dong L, et al. Genetic variation of ITGB3 is associated with asthma in Chinese Han children. PloS One 2013; 8: e56914

25. Etlik O, Koksal V, Arican-Baris ST, Baris I. Development and validation of a cost-effective in-house method, tetraprimer ARMS PCR assay, in genotyping of seven clinically important point mutations. Mol Cell Probes 2011; 25: 177-81.

26. Mikkelsson J, Perola M, Laippala P, et al. Glycoprotein IIla PI(A) polymorphism associates with progression of coronary artery disease and with myocardial infarction in an autopsy series of middle-aged men who died suddenly. Arterioscler Thromb Vasc Biol 1999; 19: 2573-8.

27. Zhu MM, Weedon J, Clark LT. Meta-analysis of the association of platelet glycoprotein IIIa PIA1/A2 polymorphism with myocardial infarction. Am J Cardiol 2000; 86: 1000-5.

28. Salonen R, Nyyssonen K, Porkkala E, et al. Kuopio Atherosclerosis Prevention Study (KAPS). A populationbased primary preventive trial of the effect of LDL lowering on atherosclerotic progression in carotid and femoral arteries. Circulation 1995; 92: 1758-64.

29. Marian AJ, Brugada R, Kleiman NS. Platelet glycoprotein IIla PIA polymorphism and myocardial infarction. N Engl J Med 1996; 335: 1071-2.

30. Weiss EJ, Bray PF, Tayback M, et al. A polymorphism of a platelet glycoprotein receptor as an inherited risk fac- tor for coronary thrombosis. N Engl J Med 1996; 334 : 1090-4.

31. Torabi R, Zarei S, Zeraati H, et al. Combination of thrombophilic gene polymorphisms as a cause of increased the risk of recurrent pregnancy loss. J Reprod Infertil 2012; 13: 89-94.

32. Yilmaz U, Zeybek U, Kahraman OT, et al. Investigation of ICAM-1 and beta3 integrin gene variations in patients with brain tumors. Asian Pacif J Cancer Prevent 2013; 14: 5929-34.

33. Bianconi D, Schuler A, Pausz C, et al. Integrin beta-3 genetic variants and risk of venous thromboembolism in colorectal cancer patients. Thromb Res 2015; 136: 865-9. 